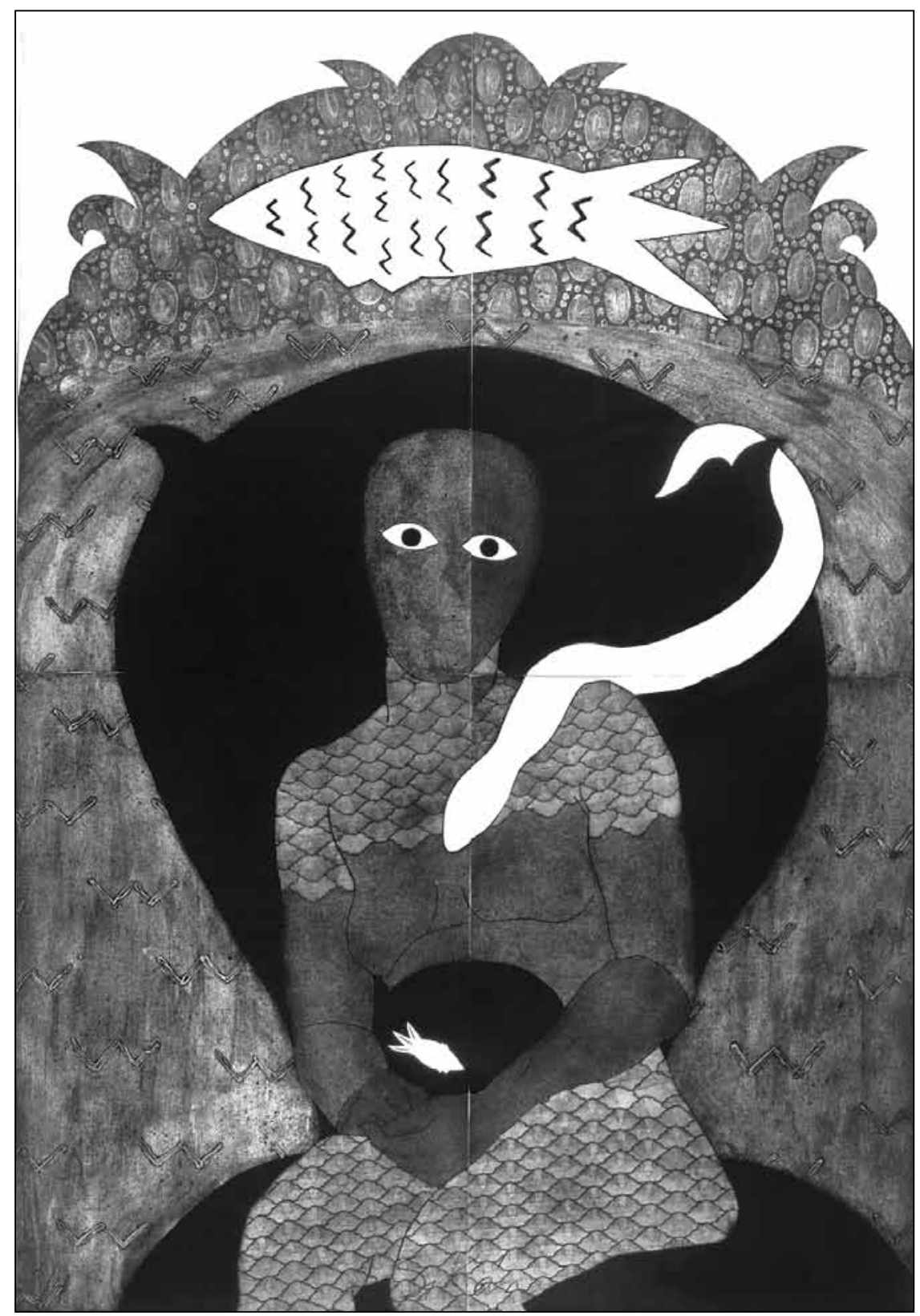

Belkis Ayón. Sikán. 1991. Colografía. Cortesía Estate Belkis Ayón. 


\section{Adelaida de Juan}

Adelaida de Juan es Profesora Consultante de Historia del Arte y Profesora Emérita de la Universidad de La Habana. Entre sus libros se encuentran Pintura cubana: temas y variaciones, En la Galería Latinoamericana, Del silencio al grito: mujeres en las artes plásticas.

\title{
Presencia afrocaribeña en la pintura cubana moderna
}

\author{
ADELAIDA DE JUAN \\ Universidad de La Habana
}

\section{RESUMEN}

El artículo analiza la compleja encrucijada de influencias que conforman la identidad cultural de la pintura cubana moderna, prestando especial atención a la definición de los caracteres afrocaribeños que contribuyen a los procesos de transculturación en Cuba. La autora plantea plantea un análisis del imaginario afrocaribeño en obras de artistas contemporáneos de gran difusión mundial; de Wifredo Lam, René Portocarrero y Manuel Mendive, a los más jóvenes y prometedores Marta María Pérez, Roberto Diago y Belkis Ayón, cuyas obras expresan las experiencias de los afrodescendientes en Cuba.

Palabras clave: Pintura, Cuba, Afrodescendientes, Wifredo Lam, René Portocarrero, Manuel Mendive, Marta María Pérez, Roberto Diago, Belkis Ayón.

\section{ABSTRACT}

The article analyzes the complexity of the crossroads of influences that configure the cultural identity of Modern Cuban painting, paying special attention to Afro-Caribbean elements that contribute to Cuban transculturation processes. The author presents an analysis of the Afro-Caribbean imaginary in paintings by world-renown artists, such as Wifredo Lam, René Portocarrero and Manuel Mendive, as well as in the art of a younger and promising generation, that comprises artists such as Marta María Pérez, Roberto Diago, and Belkis Ayón, whose work expresses the experience of Afrodescendants in Cuba.

Keywords: Painting, Cuba, Afrodescendants, Wifredo Lam, René Portocarrero, Manuel Mendive, Marta María Pérez, Roberto Diago, Belkis Ayón.

Quisiera señalar cierto carácter cubano y por tanto caribeño de nuestra pintura moderna a través de uno de los elementos significantes de considerable importancia. Este carácter implica, en esencia, uno de los miembros de nuestra nacionalidad, aquel que, viniendo de diversas fuentes étnicas africanas, se une a las provenientes de Europa (en nuestro caso, de
España) ya de por sí un híbrido secular, y, en menor medida proveniente de Asia, para dar lugar, en un proceso de varios siglos, a una nueva realidad que define nuestra identidad. Es bien sabido que nuestra mulatez no es, en las palabras de su primer y más profundo estudioso, Fernando Ortiz, "ni hibridismo insustancial, ni sincretismo, ni decoloración, 
sino simplemente, una nueva sustancia, un nuevo color, un alquitarado producto de transculturación» (12). Ortiz lo abrevió con la frase latina tertium quid. A sabiendas de las muchas discusiones surgidas alrededor del término «afrocubano» que él creara en 1906, Ortiz mantuvo su uso al considerar que señalaba «el apellido» que permite una completa identificación genealógica. Es en este sentido que usaré tal «apellido» para dirigir la atención a la presencia de elementos en algunas obras o autores que aluden a formas y temas derivados de la ascendencia africana. Presente en toda la cuenca caribeña, el sincretismo cultural se hará sentir en el mundo del arte en múltiples ídolos, fetiches, altares, pinturas religiosas en diversas formas, «firmas,» pinturas rituales, etc. Con otras manifestaciones, especialmente evidentes en la música y la danza, constituirá una profunda base para elementos diferentes de aquellos de los opresores seculares. Quisiera ahora tocar brevemente la imaginería afrocubana desarrollada por algunos pintores modernos justamente considerados de alto valor en el mundo contemporáneo del arte.

Un caso paradigmático de la incorporación consciente a una obra de significado universal de la esencia transculturada de nuestro pueblo puede hallarse en la vasta obra de Wifredo Lam. Nacido en 1902 en Sagua la Grande, una ciudad provinciana en el centro de Cuba (donde descansan sus restos desde 1982), y después de pasar muchos años en Europa, su expresión definitiva tendrá lugar en Cuba, a partir de obras como «La silla»y, sobre todo, «La jungla,» ambas pintadas en 1943. Ya Lam conocía del arte africano por los museos europeos, así como sabía de la asimilación de los valores expresivos de esas obras por artistas de vanguardia encabezados por Picasso. Sobre todo, había ocurrido un hecho muy importante para la obra de Lam: su regreso al país natal. Debe tenerse presente que ejecutó notables dibujos florales para ilustrar la edición cubana (1943) del Cabier d'un retour au pais natal de Aimé Césaire. El reencuentro de Lam con su medio original será decisivo para la creación de su obra principal. Desechando la idea primaria que ciertos autores han atribuido a su pintura por el hecho de haber tenido un padre chino y una madre mulata (que ha llevado a algunos folkloristas a hablar de la «naturalmente asiática perspectiva» de su dibujo y del «ritmo tam-tam» de su composición, no hay dudas de que nuestro pintor ha sabido captar ciertas esencias de nuestra realidad en una perspectiva universal y personal al mismo tiempo. De hecho, la pintura de Lam no es de ningún modo descriptiva de elementos que representen ceremonias religiosas, ídolos o ritos. Con pocas líneas, coloca ciertos detalles que funcionan como asideros en sus detalles; sus imágenes sugieren antes que definen: la herradura, las tijeras, el cuchillo, la vasija, los cuernos, las flechas, la rueda. Cada objeto es independiente del contexto principal y se sostiene de por sí a modo de señalar lo necesario para la imaginación del espectador y promover su participación. En ningún punto esta pintura deletrea a Changó (deidad yoruba dueña del trueno y los rayos que equivale a la católica Santa Bárbara), o a Ogún (deidad yoruba de la guerra y la lucha, equivalente a San Pedro), o a Ochún (deidad yoruba del amor equivalente a la Caridad del Cobre, patrona de Cuba), ni a ninguna otra deidad: el artista solo los señala en el amplio espectro de su imaginación.

La simbología de Lam se refiere a uno de los «apellidos» africanos estudiados por Ortiz. Temas carnales aluden a la mujer con una referencia constante, fundamentalmente basada en los senos maternos que cuelgan como frutas maduras. Lam creó repetidamente una extraordinaria figura femenina cuyo rostro es una máscara o un estilizado instrumento dentado. La presencia masculina se da sobre todo por medio de los cuernos punzantes. En todos los casos, el ser humano no será mostrado con sus contornos tradicionales: sus elementos, a veces disjuntos, tienen una considerable independencia en tanto su expresión, como puede observarse en los pies y las manos que se agigantan al posarse firmemente sobre la tierra; en ocasiones, los ojos, desorbitados, se muestran en superficies romboidales que recuerdan los íremes ñáñigos (pequeños diablos abakuá). Pero el principal elemento simbólico en la obra de Lam se encuentra en sus motivos de fronda tratados repetidamente. Cañas de azúcar, hojas de palma, maíz, tabaco y plantas de todo tipo, siempre en flor en nuestras

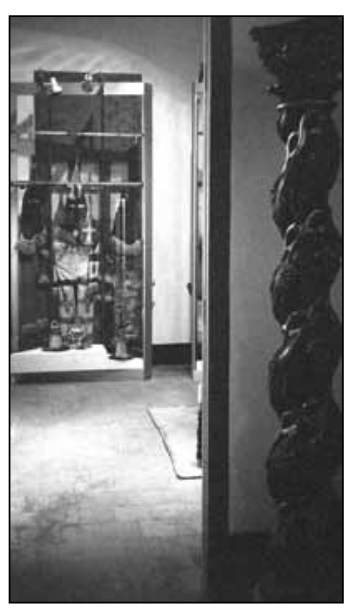

Íreme. Colección Fernando Ortiz. Casa de Africa. La Habana, Cuba. Fotografía de José Gomariz.

Presencia afrocaribeña en la pintura cubana moderna

ADELAIDA DE JUAN 
tierras, se observan en muchas de las pinturas más conocidas de nuestro artista, sobre todo a partir de la década del 40 y «La jungla». Allí alcanzan un grado supremo como elementos característicos de Lam y puede observarse cómo se entretejen con símbolos sexuales, las máscaras y las tijeras, los cuernos y los rabos. Se adelantan y retroceden, son fondo y primer plano al mismo tiempo, vegetal y animal entretejidos, creación y destrucción, mito y realidad. Este carácter alegórico usa signos que se remiten a una lejana fuente africana elaborada en nuestras tierras de muchos modos.

Otros artistas cubanos han trabajado, a partir de la década de 1930, con temas provenientes de los atributos y ritos de diversas creencias mítico-religiosas de raíces africanas. Obras de Roberto Diago (1920-1955), Portocarrero (1912-1985), Manuel Mendive (1944) y, más recientemente, a partir de la década de 1990, algunos artistas jóvenes, como Marta María Pérez (1959), Belkis Ayón (1967-1999), Roberto Diago (1971), han encontrado en diversas fuentes de raíz africana el punto de partida para sus creaciones. Quisiera detenerme primeramente en la notable obra de René Portocarrero. Su interés encontró diversas direcciones durante la década de los años 40, pintando sobre lienzo o trabajando en un mural de cerámica obras en las cuales la imaginería de los brujos yoruba constituyen el punto focal: la figura sostiene el gallo del sacrificio ritual mientras el fondo se llena de elementos alados, multiplicidad de hojas vegetales y cuernos. El empleo de cuernos por brujos afrocubanos a menudo ha sido empleado en una obvia alusión a Obatalá, una de las mayores deidades del panteón yoruba, vinculado a la católica Virgen de las Mercedes. En varias ocasiones, el artista ha repetido la figura de Santa Bárbara, generalmente con su reluciente espada mientras su ropaje toca predominantemente el color rojo, una de las tonalidades de su equivalente Changó. También Portocarrero ha insistido en los «Diablitos,» nombre generalmente dado a los africanos vestidos en la moda ancestral durante las festividades que permitían a los esclavos estar en las calles durante la danza africana del Bembé.

En sus repetidas series sobre los Carnavales, a partir de los años 60, Portocarrero logrará expresiones extraordinarias sobre este tema. El artista se coloca en el vórtice del carnaval; este es, desde tiempos ancestrales, un festival polisémico que, a lo largo del Caribe, adquiere nuevas dimensiones. En sus atributos hay una tradición viva donde originalmente los elementos esclavos sobreviven y son ahora parte de la riqueza cultural de la nación. En su tratamiento de los carnavales de los años 70, Portocarrero ha suprimido muchos de los elementos que eran notables en sus series anteriores sobre el tema. De este modo, la entrada del movimiento y el ritmo internos del carnaval se han hecho más fluidos, haciendo alusión a la original dicotomía del carnaval caribeño en tiempo y espacio (mediodía o atardecer, calle abierta y salón cerrado) que antes indicaba. Por eso en sus obras de esta temática, el artista nos sumerge en un carnaval en el cual el sincretismo ha devenido parte sustancial; de ahí que, en sus Carnavales, a diferencia de otras versiones que han sido realizadas durante siglo y medio, no hay un inicial espacio vacío que separa al espectador de la escena. Para Portocarrero, su carnaval es el lugar en el cual nos movemos, respiramos y vibramos con su acompasado ritmo.

Tres décadas después de la obra definitoria de Lam, una nueva promoción de artistas comienza su producción; surgen y se forman en condiciones bien diferentes de las que rodearon las generaciones previas y se integran, con carácter propio, a la ininterrumpida línea del arte cubano moderno. Como hiciera Lam durante los años de la década de los cuarenta, un artista en particular buscará - encontrará como acertadamente apuntó Picasso- su mundo expresivo en las raíces de sus ancestros africanos. Manuel Mendive también recibió un inicial aprendizaje académico, en La Habana, pero rápidamente lo abandonó para desarrollar lo que sería su propio estilo, radicalmente diferente del de Lam en cuanto a recrear un universo de arte. En él, basado en elementos africanos, hay al inicio un voluntario primitivismo que muestra su propia escogida temática y su simbolismo. Mendive, a su manera, mantiene una tradición fuertemente enraizada de nuestro pueblo: el de su familia inmediata. Lejos de abjurar de las tradiciones de sus ancestros yoruba - los ritos, los ritmos, los cantos, el lenguaje - Mendive los fortalecerá con el entrenamiento recibido. En muchas de sus escenas aparece una figura de doble rostro. Alude a Eleguá, una de las deidades más usadas en los ritos de la santería: abre y cierra caminos, tiene que ver con la risa y el llanto, con la vida y la muerte. Este es uno de los más reiterados recordatorios en 
la obra de Mendive y es uno de sus modos de imbricar una mitología simbólica con la realidad personal.

Su recuento histórico también tendrá una mirada doble. El artista mirará hacia el pasado para revivir escenas de la participación de nuestros ancestros africanos en escenas dolorosas, pero también en sus figuras heroicas como Maceo, Martí, Che Guevara, vinculados con Oyá, diosa del cementerio, en escenas de lucha por la libertad. Después de la década de 1980, Mendive continuará ofreciendo nuevas expresiones que revelan cambios en la recreación de la base yoruba. Realiza performances espectaculares en los que combina body-art con cantos, danzas y animales rituales, que a menudo desbordan los recintos del museo y la galería para salir a la calle, donde las gentes se le unen espontáneamente. Mendive ha usado en varios modos la pintura corporal y ha pasado luego a la escultura blanda, cuyo material voluntariamente adopta posiciones diversas. En años recientes, Mendive ha insistido en la pintura (acrílicos) y también ha incursionado en las esculturas de pequeño formato, generalmente trabajadas en bronce. En todas estas variantes de medios, se mantiene fiel al impulso proveniente de las creencias ancestrales y las creaciones que de ellas emanan.

Quisiera ahora detenerme en la obra de Belkis Ayón. A diferencia de otros artistas - como, por ejemplo, Roberto Diago, que privilegian la combinatoria de diversas figuras alegóricas en el lienzo sobre el cual manejan con preferencia el acrílico- Ayón trabaja con otro corpus legendario de origen africano, presente en nuestra cultura desde el siglo XIX: la sociedad secreta de ayuda mutua de los abakuá, también conocidos como de los ñáñigos. La prohibición en esta sociedad de las mujeres y los homosexuales tiene su origen en el complejo cultural carabalí: una mujer, Sikán, captura accidentalmente el maravilloso pez Tanze que otorga poder y gloria a su dueño. Los esfuerzos vanos para recapturar su voz una vez muerto dan como resultado el sacrificio ritual de Sikán. Ayón toma esta figura mítica una y otra vez en colografías. Ha declarado que «La leyenda de Sikán es un tema con el que he trabajado desde que estaba en la Escuela de Arte, y lo que siempre me ha interesado ha sido la condición de víctima de la figura femenina». Ella hace de Sikán un ser visible: exiliada, expulsada de la sociedad, al final asesinada: Ayón hace una doble trans- gresión. Por una parte, le da forma a la mujer, con atributos sagrados, cuando su representación visual está estrictamente prohibida por los ñáñigos. Por otra parte, se proyecta como una mujer en una sociedad patriarcal aún machista. De cierto modo, la transgresión, según los textos de Foucault, se convierte en trabajo en el límite del discurso, en el espacio donde el Otro gana espacio.

Otra artista que enriquece su obra con alusiones a la santería es Marta María Pérez. Ha reiterado en numerosas ocasiones que «Todo tiene que ver con mi vida, aunque solo sea como un punto de partida.» Pérez utiliza la autofotografía en blanco y negro como medio expresivo, siempre basado en los dichos y creencias populares nacidos del rico acervo de la santería. Respeta los colores religiosos y los atributos de los santos y deidades cuando compone sus fotografías, aun cuando los colores se pierden en el tratamiento en blanco y negro. Ella siempre es el personaje principal de su obra - su compañero solo aprieta el obturador $-y$ asume diversas posiciones y atributos fieles a los rituales de la santería. Usa su propio cuerpo para su trabajo porque siente difícil expresarse fielmente a través de otro cuerpo. En este rasgo, ella se aproxima a varias mujeres $-\mathrm{y}$ algunos hombres - quienes, como Cindy Sherman o, anteriormente, Ana Mendieta, mantienen sus propias imágenes como únicas protagonistas de su obra. Además de varios objetos como coronas, paños blancos, cuentas de bisutería, etc., que apuntan a diversas deidades, a veces usa barro, uno de los elementos que hace referencia a Eleguá. Marta María Pérez compone una perfecta mise-en-scene para sus fotografías en blanco y negro que en ocasiones son denominadas fotografías conceptuales. Decididamente no es un performance capturado por la cámara para así congelar un proyecto. Es una imagen fija en la cual, como ha expresado la artista, «todo tiene que ver conmigo pero no quiero personalizar, prefiero ser genérica».

Solo he mencionado a algunos artistas que han enriquecido su expresión con las fuentes culturales de las raíces africanas de nuestra nacionalidad. La apropiación del mundo míticoreligioso de los descendientes de africanos en tierras caribeñas se vincula a las tendencias actualmente de moda que se nutrieron original-
Presencia afrocaribeña en la pintura cubana moderna

ADELAIDA DE JUAN 
mente del período negro picassiano basado, a su vez, en la antigua escultura africana, en una suerte de looping-the-loop. Los caribeños han elaborado un arte que se ha nutrido de la herencia africana vigente desde los tiempos de la economía colonial de la plantación. En diversos países de la zona, la presencia africana se manifiesta en el arte reciente y constituye una producción intensa y variada.

\section{Bibliografía}

Ortiz, Fernando. «Preludios étnicos de la música afrocubana». Revista Bimestre $\mathrm{Cu}$ bana, 59, (1947): 5-194.

Fecha de recepción: 23/01/2014

Fecha de aceptación: 7/10/2014

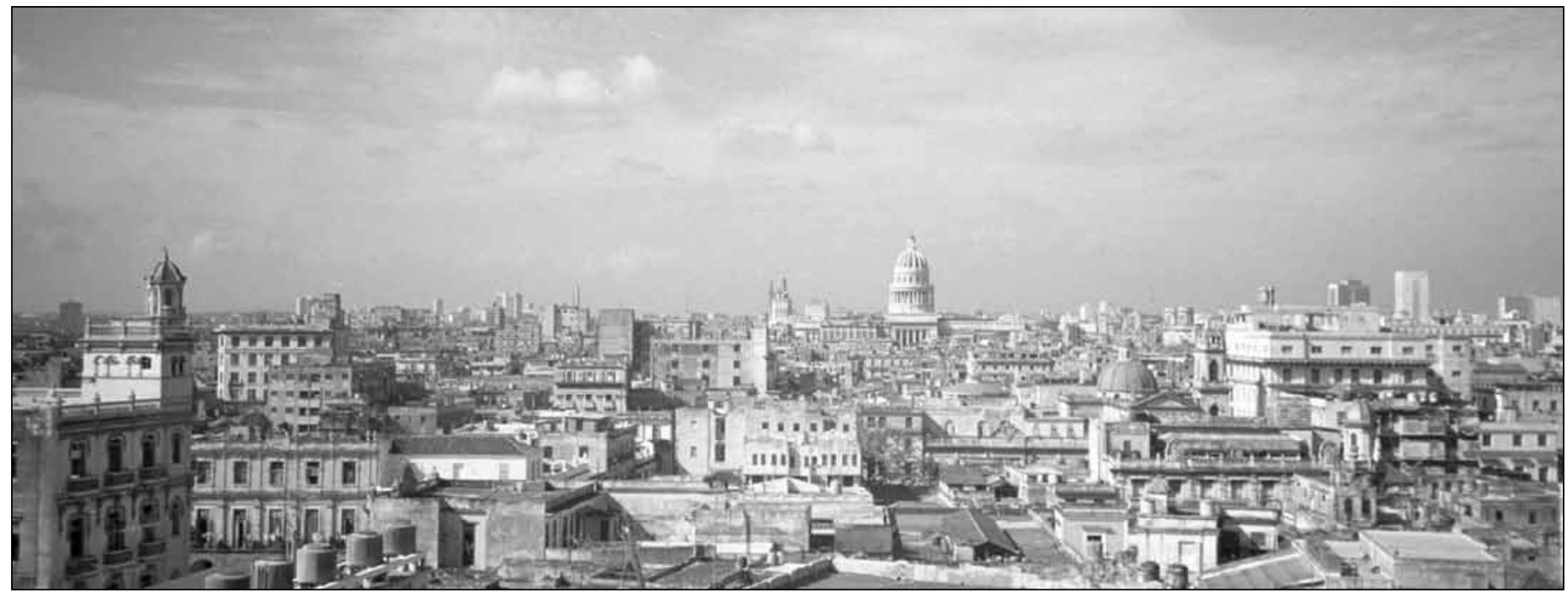

La Habana. Fotografía de José Gomariz. 